\title{
Prior exposure to stress delays extinction but does not modify reinstatement of nicotine-induced conditioned place preference
}

\author{
Rodrigo M. Leão, Fábio C. Cruz and Cleopatra S. Planeta \\ Universidade Estadual Paulista, Brazil
}

\begin{abstract}
Studies in humans suggest that exposure to stress is related to relapse to tobacco use. The reinstatement of conditioned place preference (CPP) provides a simple, noninvasive and easy approach to investigate the mechanisms for drug relapse. The present study investigated whether repeated exposure to stress could change the extinction and reinstatement of nicotineinduced CPP. Adult male Wistar were exposed to restraint-stress for 2 hours/daily for 7 days, while the control-group was left undisturbed during this period. One day after the last stress session the CPP protocol was carried out. Nicotine produced a place preference to the compartment paired with its injections during conditioning (.16 mg/kg, s.c.; four drug sessions). Once established, nicotine place preference was extinguished by alternate exposure to each compartment after a saline injection (four exposures to each compartment). The animals that did not show extinction of CPP were submitted to two other extinction sessions. Following this extinction phase, the reinstatement of place conditioning was investigated following a priming injection of nicotine. Both control and stress groups showed reinstatement of CPP. The percentage of rats from the stress group that extinguished nicotine-CPP in the first and second test was lower as compared to the control group. In conclusion, stress delayed the extinction of the nicotine-induced CPP, but did not modify the reinstatement.
\end{abstract}

Received 27 February 2010; received in revised form 28 May 2010; accepted 28 May 2010. Available on line 26 June 2010

\section{Introduction}

According to the World Health Organization, cigarette smoking is the leading cause of preventable death worldwide (World Health Organization, 2009). One-third of the world's population smoke tobacco, and half of the smoking population dies from a smoking-related disease. Much evidence suggests that nicotine, which acts at neuronal nicotinic acetylcholine receptors, is the main active component in tobacco responsible for tobacco addiction (Stolerman \& Jarvis, 1995; Wonnacott, Sidhpura \& Balfour, 2005).

Rodrigo M. Leão, Laboratory of Pharmacology, School of Pharmaceutical Sciences, Universidade Estadual Paulista UNESP; Graduate Program in Physiological Sciences, UFSCar/ UNESP. Fábio C. Cruz, Laboratory of Pharmacology, School of Pharmaceutical Sciences, Universidade Estadual Paulista UNESP. Cleopatra S. Planeta, Laboratory of Pharmacology, School of Pharmaceutical Sciences, Universidade Estadual Paulista - UNESP; Graduate Program in Physiological Sciences, UFSCar/UNESP. Correspondence regarding this article should be directed to: Cleopatra S. Planeta, Laboratory of Pharmacology, School of Pharmaceutical Sciences, Univ. Universidade Estadual Paulista - UNESP, Rod. Araraquara-Jaú Km 1, Araraquara, SãoPaulo, Brazil, 14801-902.Phone: +55-16-3301-6981. Fax: +55-16-3301-6980. E-mail: cplaneta@fcfar.unesp.br
Tobacco addiction is a process that usually begins with the occasional use of the substance and evolves into compulsive use (O’Brien, Volkow \& Li, 2006). Moreover, tobacco addiction is associated with high rates of relapse to drug use even after prolonged periods of abstinence (Shalev, Grimm \& Shaham, 2002; Fiore, 2000).

Stressful experiences appear to strongly influence the susceptibility to drug-taking behavior (Sinha, Catapano \& O'Malley, 1999). Exposure to stressful events has been related to the initiation and maintenance of drug use and relapse (Gawin, 1991; Sinha, 2001; Gordon, 2002; Goeders, 2003; Weiss, 2005). Exposure to stress appears to increase the number of cigarettes smoked and is strongly associated with craving and relapse to tobacco smoking (Cohen \& Lichtenstein, 1990; Kassel, Stroud \& Paronis, 2003; Niaura \& Abrams, 2002).

Stress can increase the reinforcing effects of substances of abuse (Will, Watkins \& Maier, 1998; DerAvakian et al., 2005). Many studies have shown that exposure to stress can facilitate drug-induced conditioned place preference (CPP; Capriles \& Cancela, 1999; Del Rosario Capriles \& Cancela, 2002). For example, previous stress exposure was shown to increase the intensity of the expression of morphine-induced CPP (Will et al., 1998).

Clinical studies have demonstrated that exposure to stress or simply the presentation of stress-related imagery can induce relapse to drug seeking in humans (Shiffman, 
Read \& Jarvik, 1985; Lamon \& Alonzo, 1997; Brady \& Sonne, 1999; Sinha, 2001; Sinha et al., 1999).

Two animal models have proven especially useful for studying relapse, reinstatement of self-administration (Carroll, 1985; Lê \& Shaham, 2002; Lu, Grimm, Shaham \& Hope, 2003), and reinstatement of CPP (Mueller \& Stewart, 2000; Itzhak \& Martin, 2002; Lu et al., 2005; Biala \& Budzynska, 2006). The same stimuli that can reinstate selfadministration are able to induce the reinstatement of CPP (Aguilar, Rodríguez-Arias \& Miñarro, 2009). Preclinical studies have shown that stress can reinstate cocaine, amphetamine, morphine, and heroin self-administration (de Wit \& Stewart, 1981; Shaham, Adamson, Grocki \& Corrigall, 1997; Buczek, Lê, Wang, Stewart and Shaham, 1999; LeSage, Burroughs, Dufek, Keyler \& Pentel, 2004). Similarly, several studies have shown that stress exposure reinstates opioid-, cocaine-, and nicotine-induced CPP (Will et al., 1998, 2004; Der-Avakian et al., 2005; DerAvakian et al., 2006; Leão, Cruz \& Planeta, 2009).

In rats, intermittent footshock reinstates nicotine selfadministration up to 15 days after extinction (Buczek, Lê, Wang \& Stewart, 1999). We recently showed that exposure to acute restraint stress reinstated nicotineinduced CPP 15 days after the extinction of this behavior (Leão, Cruz \& Planeta, 2009). Moreover, exposure to footshock stress prolonged the process of extinguishing morphine-induced CPP (Lu, Ceng \& Huang, 2000).

Despite the strong influence of stress on relapse to tobacco use, the effects of prior exposure to repeated stress on extinction and reinstatement of nicotine-induced CPP has not been investigated. Thus, the present study investigated whether repeated stress exposure affects the extinction and reinstatement of nicotine-induced CPP.

\section{Methods}

\section{Subjects}

Subjects were adult male Wistar rats weighing 225$250 \mathrm{~g}$ from the animal breeding facility of the Universidade Estadual Paulista - UNESP. Groups of four to five animals were housed in plastic cages $(32 \mathrm{~cm}$ width $\times 40 \mathrm{~cm}$ length $\times 16 \mathrm{~cm}$ height) in a room maintained at $23 \pm 21^{\circ} \mathrm{C}$. Rats were kept on a $12 \mathrm{~h} / 12 \mathrm{~h}$ light/dark cycle (lights on at 07:00 h) and were allowed free access to food and water. Each animal was used only in one experimental procedure. All experiments were performed during the light phase between 08:00 h and 17:00 h. Each experimental group consisted of 10 to 12 animals per group.

The experimental protocol was approved by the Ethics Committee for Use of Human or Animal Subjects of the School of Pharmaceutical Science, UNESP (CEP-13/2004), and the experiments were conducted according to the ethical principles of the Brazilian College of Animal Experimentation, which are based on the National Institutes of Health Guidelines for the Care and Use of Laboratory Animals.
Drug

(-) - Nicotine 99\% was obtained from SigmaAldrich (St Louis, MO, USA). The dose of nicotine was chosen based on previous experiments conducted in our laboratory (Leão, Cruz \& Planeta, 2009)

\section{Repeated stress paradigm}

The animals were allocated to two groups: control and chronic restraint stress. Animals in the chronic restraint stress group were restrained in plastic cylinders ( $20.0 \mathrm{~cm}$ length $\times 5.5 \mathrm{~cm}$ internal diameter) $2 \mathrm{~h}$ daily for 7 days beginning at 10:00 h. The control group was left undisturbed, with the exception of cleaning the cages.

\section{Reinstatement of nicotine-induced CPP}

The testing apparatus for the CPP paradigm consisted of Plexiglas boxes with two compartments of equal size $(30.0 \mathrm{~cm}$ length $\times 21.0 \mathrm{~cm}$ width $\times 30.0 \mathrm{~cm}$ height $)$ separated from a small central gray area $(15.0 \mathrm{~cm}$ length $\times$ $30.0 \mathrm{~cm}$ width $\times 30.0 \mathrm{~cm}$ height) by removable guillotine doors. One compartment had white walls and a thin parallel grid floor, and the other compartment had black and white stripes on the walls and a grid with small holes on the floor. The central gray area constituted a "neutral" chamber. The testing boxes were kept in a soundproof room with dim 40 lux illumination.

The CPP reinstatement procedure consisted of the following phases: pre-conditioning, conditioning, post-conditioning, extinction, and reinstatement. This method was similar to that described by Mueller, Perdikaris \& Stewart, (2002).

Pre-conditioning (PRE-TEST): During this phase, each rat was placed in the neutral compartment with the guillotine doors removed to allow access to the entire apparatus for 15 minutes for 3 days. On day 3, rats were placed in the apparatus and videotaped for 15 minutes to record the time spent in each compartment. Approximately 20\% of the animals displayed strong unconditioned aversion $(<$ $15 \%$ of session time) or preference $(>85 \%)$ for one of the compartments and were thus excluded from the study.

Conditioning: Animals were randomly assigned to drug or saline administration. Conditioning was performed using a protocol consisting of eight alternating subcutaneous (s.c.) injections of nicotine $(.16 \mathrm{mg} / \mathrm{kg}$ ) or saline. Injections were administrated immediately before confinement to one of the two compartments for 30 minutes. In each group, half of the animals that received nicotine were confined to the preferred compartment, and the other half were confined to the initially non-preferred compartment. Conditioning sessions were conducted twice per day at 4 hour intervals. The control group received saline every day in both compartments. The neutral chamber was never used during conditioning and was blocked by guillotine doors.

Conditioning test (TEST): The test was conducted 24 hours after the last conditioning session. Each rat was placed in the neutral compartment with the guillotine 
doors removed to allow access to the entire apparatus. The time spent in each compartment was recorded for 15 minutes, similar to the pre-conditioning phase. Nicotine or saline was not injected before the tests.

Extinction: Beginning the day after the CPP test, rats underwent extinction by pairing both compartments with saline for 4 days. Twenty-four hours after the last extinction session, the extinction test was performed as described in the conditioning test. The animals that did not show extinction of CPP were subjected to two more extinction sessions until all of the animals exhibited extinction of CPP.

Reinstatement (REINST): Twenty-four hours after the last extinction session, drug-induced reinstatement of nicotine-induced CPP was evaluated. Separate groups of rats received a priming injection of nicotine $(.16 \mathrm{mg} /$ $\mathrm{kg}$, s.c.) or $.9 \%$ saline and were then immediately tested for reinstatement of CPP. During this reinstatement test, each rat was placed in the neutral compartment with the guillotine doors removed to allow access to the entire apparatus for 15 minutes, and the time spent in each compartment was measured as described above.

\section{Statistics}

The behavioral data is expressed as means \pm SEM of CPP score of 10 to 12 animals per group. The conditioned score is expressed by the ratio between the time spent in the drug-paired and the time spent in both compartments (drug and saline paired), (i.e. total time minus time spent in the neutral chamber) multiplied by 100 .

Levene tests for homogeneity of variance were performed to the behavioral data. Levene did not show statistically significant differences, indicating the homogeneity of variance.

Thus the reinstatement of CPP was analyzed by threeway ANOVA for repeated measured [Stress (stress and nonstress), treatment (saline and nicotine), and phases (PRECOND, COND, EXT and REINST)]. The phase was used as repeated-measured. When a significant $(p<.05)$ main effect was observed F-tests for contrast analysis were applied.
The $\chi^{2}$ test was applied to analyze the percentage of animals that extinguished the $\mathrm{CPP}$ across the extinction tests.

\section{Results}

Three-way ANOVA revealed significant differences for the phase $\left(F_{3,156}=10.72 ; p<.001\right)$, but not for stress and treatment factors $\left(F_{1,52}=2.54 ; p=.11\right) ;\left(F_{1,52}=\right.$ $.0018 ; p<.97$; respectively). This analysis detected interaction between treatment and phases factors $\left(F_{3,156}\right.$ $=10.72 ; p<.001)$. No other interactions were observed among the factors.

Since ANOVA did not reveal significant differences for the stress factor or interaction between stress and phase factors, the stress factor was not considered for further analysis by the F-Test. The F-Test revealed an increase in the time spent in nicotine-paired compartment in the TEST when compared to PRE$\operatorname{TEST}\left(F_{1,52}=32.86 ; p<.001\right)$, indicating that nicotine induced CPP. In addition, no difference was observed comparing PRE-TEST to EXT phases $\left(F_{1,52}=.04 ; p=\right.$ $.84)$. Moreover significant differences in the time spent in nicotine-paired compartment were observed between COND and EXT phases $\left(F_{1,52}=46.55 ; p<.001\right)$. Further, significant differences in the time spent in nicotinepaired compartment were detected comparing REINST to PRE-TEST $\left(F_{1,52}=22.68 ; p<.001\right)$. No significant differences were observed between COND x REINST phases $\left(F_{1,52}=.26 ; p=.60\right)$ (Figure 1A and 1B).

No significant differences were observed in the time spent for saline group across phases.

The $\chi_{2}^{2}$ test showed that the percentage of animals that extinguished nicotine-induced CPP in the first and second extinction tests was lower in the stress group as compared to the control one $(p<.01)$ (Table 1$)$.

\section{Discussion}

In the present study we investigated whether previous exposure to repeated stress modify the extinction and

\section{STRESS GROUP}

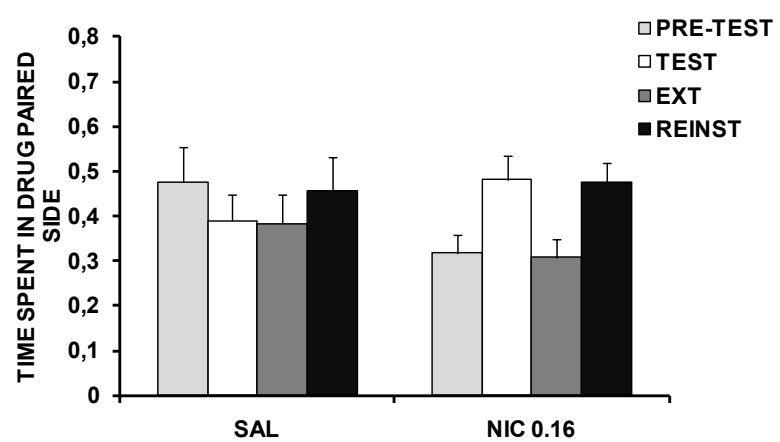

NON-STRESS GROUP

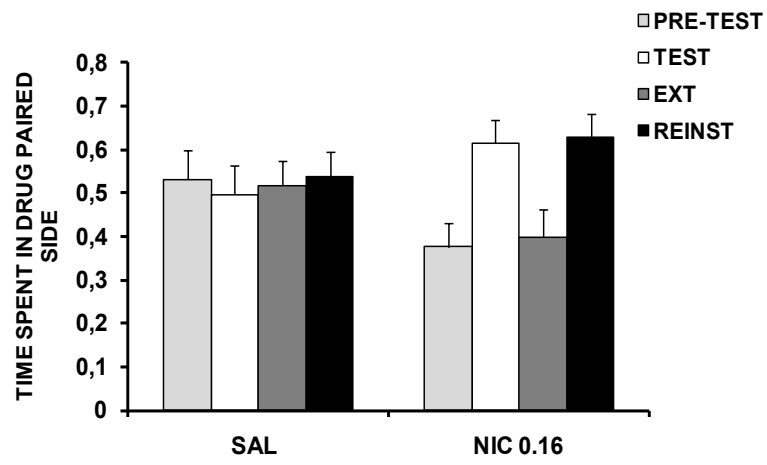

Figure 1. Acquisition, extinction, and reinstatement of nicotine-induced CPP after a priming injection of nicotine. Bars represent mean \pm SEM of CPP score ( $n=10-12$ animals per group). (A) Stress group. (B) Control group. * $p<.05$, compared with PRETEST; ${ }^{*} p<.05$, compared with EXT. 
Table 1. Percentage of animals that extinguished nicotine-induced CPP after the first, second, and third extinction test.

\begin{tabular}{cccc}
\hline Group & Extinction I & Extinction II & Extinction III \\
\hline Stress & $40 \% *$ & $60 \% *$ & $100 \%$ \\
Control & $83 \%$ & $100 \%$ & $100 \%$ \\
\hline
\end{tabular}

$* p<.01$, compared with control group.

reinstatement of nicotine-induced CPP. We observed that the exposure to stress impaired the extinction of nicotine-induced CPP but did not alter the reinstatement induced by a priming injection of nicotine.

The present results showed that previous exposure to repeated stress reduced the percentage of rats that extinguished nicotine-induced CPP after the first and second extinction test when compared to rats that were not exposed to stress, suggesting that previous stress experience can strength the conditioning to nicotine. These findings corroborate those observed by Lu, Ceng \& Huang, (2000) showing that the extinction of morphineCPP is impaired by prior exposure to foot-shock stress.

Conversely, it was demonstrated that stress facilitates the extinction of alcohol self-administration (Funk, Harding, Juzytsch \& Lê, 2005). However, there are some differences between the experiments; while we used the CPP procedure Funk, Harding, Juzytsch \& Lê, (2005) used the self-administration procedure to access the impact of stress on extinction. Furthermore, they exposed the animals to stress after the acquisition of the conditioned behavior.

The impaired extinction of nicotine-induced CPP in animals prior exposed to stress may be related to the effect of stress on the reinforcing drug properties. In fact, several studies show that both acute and repeated stress can enhance drug reinforcement (Der-Avakian et al., 2005; Goeders \& Guerin, 1994; Shaham \& Stewart, 1994; Will, Watkins \& Maier, 1998). For instance, Capriles \& Cancela (1999) showed that a single restraint stress exposure induced an enhancement of D-amphetamine-induced place preference. Furthermore, exposure to uncontrollable stress (inescapable shock) potentiated morphine-CPP. Thus, we could suggest that enhancement of drug reward could have strengthened the conditioning to nicotine making extinction of the conditioned behavior more difficult.

The mesolimbic dopamine systems are critically involved in reward of psychostimulants and nicotine (Di Chiara, 1995; Brunzell, Mineur, Neve \& Picciotto, 2009). In this sense, there is evidence that nicotine-induced CPP is coupled to an enhancement of dopaminergic activity (Spina, Fenu, Longoni, Rivas \& Di Chiara, 2006). Similarly to drug, stress also increases the activity of the dopaminergic mesocorticolimbic system (Kalivas \& Duffy, 1989; Imperato, Puglisi-Allegra, Zocchi, Scrocco,
Casolini \& Angelucci, 1990; Marinelli \& Piazza, 2002). Moreover, stress can increase drug-induced dopamine release in the NAcc (Pacchioni, Cador, Bregonzio \& Cancela, 2007). For instance, it was demonstrated that repeated food restriction stress induced an increased in dialysate dopamine in the nucleus accumbens in response to amphetamine administration (Cadoni, Solinas, Valentini \& Di Chiara, 2003).

Regarding reinstatement of nicotine-induced CPP by a priming injection of this drug, we did not observe differences in the group of animals exposed to stress as compared to the control group, i.e., both control and stress groups displayed reinstatement in the same magnitude. These results are in accordance with Funk, Harding, Juzytsch \& Lê, (2005) that demonstrated that previous stress exposure did not influence the reinstatement of cocaine self-administration. However, we cannot completely rule out the possibility the stress can alter the reinstatement of nicotine-CPP because in our study we used only one priming dose of this drug.

Even though the effects of stress on potentiating druginduced reinstatement of CPP was not evidenced in this study, recently we have reported that the exposure to one episode of restraint stress previously to the reinstatement test was able to reinstate nicotine - induced CPP one and 15 days after extinction test (Leão, Cruz \& Planeta, 2009), suggesting that although stress did not alter nicotineinduced relapse it can promote relapse by itself.

Overall, stress impaired the extinction of nicotineinduced CPP, but did not modify the reinstatement. Our findings add pre-clinical evidence that exposure to stress can difficult the abstinence to tobacco.

\section{Acknowledgements}

The authors appreciate the excellent technical assistance of Elisabete Zocal Paro Lepera and Rosana Finoti Pupim Silva. RML was supported by Fundação de Amparo à Pesquisa do Estado de São Paulo (FAPESP; 05/02336-0). CSP is a CNPq research fellow.

\section{References}

Aguilar, M.A., Rodríguez-Arias, M., \& Miñarro, J. (2009). Neurobiological mechanisms of the reinstatement of drug-conditioned place preference. Brain Research Reviews, 59, 253-277.

Biala, G., \& Budzynska, B. (2006). Reinstatement of nicotine-conditioned 
place preference by drug priming: effects of calcium channel antagonists. European Journal of Pharmacology, 537, 85-93.

Brady, K.T., \& Sonne, S.C. (1999). The role of stress in alcohol use, alcoholism treatment, and relapse. Alcohol Research and Health, 23, 263-271.

Brunzell, D.H., Mineur, Y.S., Neve, R.L., \& Picciotto, M.R. (2009). Nucleus accumbens CREB activity is necessary for nicotine conditioned place preference. Neuropsychopharmacology, 34, 1993-2001.

Buczek, Y., Lê, A.D., Wang, A., Stewart, J., \& Shaham, Y. (1999). Stress reinstates nicotine seeking but not sucrose solution seeking in rats. Psychopharmacology, 144, 183-188.

Cadoni, C., Solinas, M., Valentini, V., \& Di Chiara, G. (2003). Selective psychostimulant sensitization by food restriction: differential changes in accumbens shell and core dopamine. European Journal of Neuroscience, 18, 2326-2334.

Capriles, N., \& Cancela, L.M. (1999). Effect of acute and chronic stress restraint on amphetamine-associated place preference: involvement of dopamine $\mathrm{D}_{1}$ and $\mathrm{D}_{2}$ receptors. European Journal of Pharmacology, 386, 127-134.

Cohen, S., \& Lichtenstein, E. (1990). Perceived stress, quitting smoking, and smoking relapse. Health Psychology, 9, 466-478.

Carroll, M.E. (1985). The role of food deprivation in the maintenance and reinstatement of cocaine-seeking behavior in rats. Drug and Alcohol Dependence, 16, 95-109.

de Wit, H., \& Stewart, J. (1981). Reinstatement of cocaine-reinforced responding in the rat. Psychopharmacology, 75, 134-143.

Del Rosario Capriles, N., \& Cancela, L.M. (2002). Motivational effects $\mu$ - and $\kappa$-opioid agonists following acute and chronic restraint stress: involvement of dopamine $\mathrm{D}_{1}$ and $\mathrm{D}_{2}$ receptors. Behavioural Brain Research, 132, 159-169.

Der-Avakian, A., Bland, S.T., Schmid, M.J., Watkins, L.R., Spencer, R.L., \& Maier, S.F. (2006). The role of glucocorticoids in the uncontrollable stress-induced potentiation of nucleus accumbens shell dopamine and conditioned place preference responses to morphine. Psychoneuroendocrinology, 31, 653-663.

Der-Avakian, A., Will, M.J., Bland, S.T., Deak, T., Nguyen, K.T., Schmid, M.J., Spencer, R.L., Watkins, L.R., \& Maier, S.F. (2005). Surgical and pharmacological suppression of glucocorticoids prevents the enhancement of morphine conditioned place preference by uncontrollable stress in rats. Psychopharmacology, 179, 409-417.

Di Chiara, G. (1995). The role of dopamine in drug abuse viewed from the perspective of its role in motivation. Drug and Alcohol Dependence, 38, 95-137.

Fiore, M.C. (2000). Treating tobacco use and dependence: an introduction to the US Public Health Service Clinical Practice Guideline. Respiratory Care, 45, 1196-1199.

Funk, D., Harding, S., Juzytsch, W., \& Lê, A.D. (2005). Effects of unconditioned and conditioned social defeat on alcohol selfadministration and reinstatement of alcohol seeking in rats. Psychopharmacology, 183, 341-349.

Gawin, F.H. (1991). Cocaine addiction: psychology and neurophysiology. Science, 251, 1580-1586.

Goeders, N.E., \& Guerin, G.F. (1994). Non-contingent electric footshock facilitates the acquisition of intravenous cocaine selfadministration in rats. Psychopharmacology, 114, 63-70.

Goeders, N.E. (2003). The impact of stress on addiction. European Neuropsychopharmacology, 13, 435-441.

Gordon, H.W. (2002). Early environmental stress and biological vulnerability to drug abuse. Psychoneuroendocrinology, 27, 115-126.

Imperato, A., Puglisi-Allegra, S., Zocchi, A., Scrocco, M.G., Casolini, P., \& Angelucci, L. (1990). Stress activation of limbic and cortical dopamine release is prevented by ICS $205-930$ but not by diazepam. European Journal of Pharmacology, 175, 211-214.

Itzhak, Y., \& Martin, J.L. (2002). Cocaine-induced conditioned place preference in mice: induction, extinction and reinstatement by related psycostimulants. Neuropsychopharmacology, 26, 130-134.

Kalivas, P.W., \& Duffy, P. (1989). Similar effects of daily cocaine and stress on mesocorticolimbic dopamine neurotransmission in the rat. Biological Psychiatry, 25, 913-928.

Kassel, J.D., Stroud, L.R., \& Paronis, C.A. (2003). Smoking, stress, and negative affect: correlation, causation, and context across stages of smoking. Psychological Bulletin, 129, 270-304.

Lamon, B.C., \& Alonzo, A. (1997). Stress among males recovering from substance abuse. Addictive Behaviors, 22, 195-205.

Lê, A., \& Shaham, Y. (2002). Neurobiology of relapse to alcohol in rats. Pharmacology and Therapeutics, 94, 137-156.

Leão, R.M., Cruz, F.C., \& Planeta, C.S. (2009). Exposure to acute restraint stress reinstates nicotine-induced place preference in rats. Behavioural Pharmacology, 20, 109-113.

LeSage, M.G., Burroughs, D., Dufek, M., Keyler, D.E., \& Pentel, P.R. (2004). Reinstatement of nicotine self-administration in rats by presentation of nicotine-paired stimuli, but not nicotine priming. Pharmacology Biochemistry and Behavior, 79, 507-513.

Lu, L., Ceng, X., \& Huang, M. (2000). Corticotropin-releasing factor receptor type 1 mediates stress-induced relapse to opiate dependence in rats. Neuroreport, 11, 2373-2378.

Lu, L., Chen, H., Su, W., Ge, X., Yue, W., Su, F., \& Ma, L. (2005). Role of withdrawal in reinstatement of morphine-conditioned place preference. Psychopharmacology, 181, 90-100.

Lu, L., Grimm, J.W., Shaham, Y., \& Hope, B.T. (2003). Molecular neuroadaptations in the accumbens and ventral tegmental area during the first 90 days of forced abstinence from cocaine selfadministration. Journal of Neurochemistry, 85, 1604-1613.

Marinelli, M., \& Piazza, P.V.(2002). Interaction between glucocorticoid hormones, stress and psychostimulant drugs. European Journal of Neuroscience, 16, 387-394.

Mueller, D., Perdikaris D., \& Stewart J. (2002) Persistence and druginduced reinstatement of a morphine-induced conditioned place preference. Behavioural Brain Research, 136, 389-97.

Mueller, D., \& Stewart, J. (2000). Cocaine-induced conditioned place preference: reinstatement by priming injections of cocaine after extinction. Behavioural Brain Research, 115, 39-47.

Niaura, R., \& Abrams, D.B. (2002). Smoking cessation: progress, priorities, and prospectus. Journal of Consulting and Clinical Psychology, 70, 494-509.

O'Brien, C.P., Volkow, N., \& Li, T.K. (2006). What's in a word? Addiction versus dependence in DSM-V. American Journal of Psychiatry, 163, 764-765.

Pacchioni, A.M., Cador, M., Bregonzio, C., \& Cancela, L.M. (2007). A glutamate-dopamine interaction in the persistent enhanced response to amphetamine in nucleus accumbens core but not shell following a single restraint stress. Neuropsychopharmacology, 32, 682-692.

Shaham, Y., Adamson, L.K., Grocki, S., \& Corrigall W.A. (1997). Reinstatement and spontaneous recovery of nicotine seeking in rats. Psychopharmacology, 130, 396-403.

Shaham, Y., \& Stewart, J. (1994). Exposure to mild stress enhances the reinforcing efficacy of intravenous heroin self-administration in rats. Psychopharmacology, 114, 523-527.

Shalev, U., Grimm, J.W., \& Shaham, Y. (2002). Neurobiology of relapse to heroin and cocaine seeking: a review. Pharmacological Reviews, 54, 1-42.

Shiffman, S., Read, L., \& Jarvik, M.E. (1985). Smoking relapse situations: a preliminary typology. International Journal of the Addictions, 20, 311-318.

Sinha, R., Catapano, D., \& O’Malley, S. (1999). Stress-induced craving and stress response in cocaine dependent individuals. Psychopharmacology, 142, 343-351.

Sinha, R. (2001). How does stress increase risk of drug abuse and relapse? Psychopharmacology, 158, 343-359.

Spina, L., Fenu, S., Longoni, R., Rivas, E., \& Di Chiara, G. (2006). Nicotine-conditioned single-trial place preference: selective role of nucleus accumbens shell dopamine $\mathrm{D}_{1}$ receptors in acquisition. Psychopharmacology, 184, 447-455.

Stolerman, I.P., \& Jarvis, M.J. (1995). The scientific case that nicotine is addictive. Psychopharmacology, 117, 2-10.

Weiss, F. (2005). Neurobiology of craving, conditioned reward and relapse. Current Opinion in Pharmacology, 5, 9-19.

Will, M.J., Watkins, L.R., \& Maier, S.F. (1998). Uncontrollable stress potentiates morphine's rewarding properties. Pharmacology Biochemistry and Behavior, 60, 655-664.

Will, M.J., Der-Avakian, A., Bland, S.T., Grahn, R.E., Hammack, S.E., Sparks, P.D., Pepin, J.L., Watkins, L.R., \& Maier, S.F. (2004). Eletrolytic lesion and pharmacological inhibition of the dorsal raphe nucleus prevent stressor potentiation of morphine conditioned place preference in rats. Psychopharmacology, 171, 191-198.

Wonnacott, S., Sidhpura, N., \& Balfour, D.J. (2005). Nicotine: from molecular mechanisms to behaviour. Current Opinion in Pharmacology, 5, 53-59.

World Health Organization (2009). International statistical classification of diseases and related health problems. Geneva: World Health Organization. 